\title{
Nocturnal carbon efflux: reconciliation of eddy covariance and chamber measurements using an alternative to the $u$.-threshold filtering technique
}

\section{Eva Van Gorsel, Ray Leuning, Helen A. Cleugh, Heather Keith \& Tanja Suni}

To cite this article: Eva Van Gorsel, Ray Leuning, Helen A. Cleugh, Heather Keith \& Tanja Suni (2007) Nocturnal carbon efflux: reconciliation of eddy covariance and chamber measurements using an alternative to the u.-threshold filtering technique, Tellus B: Chemical and Physical Meteorology, 59:3, 397-403, DOI: 10.1111/j.1600-0889.2007.00252.x

To link to this article: https://doi.org/10.1111/j.1600-0889.2007.00252.x

\section{(c) 2007 The Author(s). Published by Taylor \& Francis.}

冓 Published online: 18 Jan 2017.

Submit your article to this journal

Џلll Article views: 196

Q View related articles $₫$

7 Citing articles: 8 View citing articles 


\title{
Nocturnal carbon efflux: reconciliation of eddy covariance and chamber measurements using an alternative to the $u *$-threshold filtering technique
}

\author{
By EVA VAN GORSEL ${ }^{1 *}$, RAY LEUNING ${ }^{1}$, HELEN A. CLEUGH ${ }^{1}$, HEATHER KEITH ${ }^{2}$ \\ and TANJA SUNI ${ }^{1}$, ${ }^{1}$ CSIRO Marine and Atmospheric Research, P.O. Box 1666, Canberra, ACT 2601, Australia; \\ ${ }^{2}$ CSIRO Climate Program, PO Box 3023, Canberra, ACT 2601, Australia
}

(Manuscript received 28 April 2006; in final form 25 October 2006)

\begin{abstract}
Micrometeorological measurements made on single towers often underestimate nighttime respiration of terrestrial ecosystems because they cannot account for vertical and horizontal advection, thereby causing systematic errors in estimates of net ecosystem carbon exchange. We show that there is a maximum in the sum of the turbulent flux and change in storage of $\mathrm{CO}_{2}$ in the early evening, $R_{\max }$, that is in close agreement with concurrent and independent estimates of net carbon exchange from soil and plant chambers. We hypothesize that the peak occurs because there is a time delay between the onset of radiative cooling and the development of temperature gradients that are strong enough to initiate thermally-driven horizontal and vertical flows that remove the stored $\mathrm{CO}_{2}$. We propose taking advantage of this time delay to develop relationships between $R_{\max }$ and soil temperature and moisture. The new parameterization leads to realistic values of nighttime respiration, and therefore to improved estimates of net ecosystem exchange.
\end{abstract}

\section{Introduction}

The eddy covariance method is being used to measure the exchange of carbon dioxide $\left(\mathrm{CO}_{2}\right)$, water vapor and energy between the land and atmosphere at over 400 stations globally. The major goal of these studies is to assess annual carbon budgets of the ecosystems studied and to develop improved mechanistic understanding of their responses to present and future climate. Data are also used to parameterize land-surface models (Wang et al., 2001) and to validate regional and continental carbon budgets (Baldocchi et al., 1996). Typically, turbulent fluxes are measured on a single tower at one or more heights above the vegetation, supplemented by measurements of concentration at several heights. The net exchange of $\mathrm{CO}_{2}$ between the underlying vegetation and the atmosphere is then assumed to equal the sum of the turbulent flux and the rate of change in storage of $\mathrm{CO}_{2}$ in the layer of air below the measurement height, an assumption that is correct only in the absence of horizontal and vertical flux divergences. Such conditions are more easily obtained over uniform vegetation on landscapes with flat to moderate topography during the daytime, when the air flow

\footnotetext{
*Corresponding author.

e-mail: eva.vangorsel@csiro.au

DOI: $10.1111 / \mathrm{j} .1600-0889.2007 .00252 . x$
}

is well-mixed and unstably stratified, but are difficult to obtain when air flow is inhomogeneous under stable conditions that often occur at night under clear skies and low wind speeds. This can lead to systematic errors between estimates of net daytime and nighttime fluxes of $\mathrm{CO}_{2}$, which are often of similar magnitude but opposite in sign, and hence to large errors in annual ecosystem carbon budgets (Goulden et al., 1996; Moncrieff et al., 1996).

Many research groups report that the nocturnal carbon efflux $(N C E)$ is significantly underestimated by the sum of turbulent fluxes and changes in storage when compared with concurrent chamber measurements of soil and plant respiration (Goulden et al., 1996; Barford et al., 2001; Curtis et al., 2002). It has been argued on both theoretical grounds and experimental evidence that unmeasured vertical and horizontal advection is the cause of this mismatch (Aubinet et al., 2000, 2005; Finnigan and Belcher, 2004; Miller et al., 2004; Staebler and Fitzjarrald, 2004; Katul et al., 2006). One approach to resolve the problem is therefore to use a three-dimensional (3-D) instrument array to measure the net exchange (Turnipseed et al., 2003; Feigenwinter et al., 2004; Aubinet et al., 2005). However, the 3-D nature of the problem requires a large number of instruments and complex experimental designs. This is not an option for most research groups and does not allow extraction of the optimum amount of information from existing 1-D installations, so we seek an 
alternative approach to improving the estimates of $N C E$ using existing data.

Goulden et al. (1996) proposed discarding data obtained during calm, nocturnal periods because they systematically underestimated the NCE. They applied a ' $u_{*}$ filter' to eliminate data for calm situations and used the remaining data to estimate ecosystem respiration based on soil temperature. The determination of an adequate $u_{*}$ threshold is crucial, as shown by the study of Miller et al. (2004), where relatively slight variations in the threshold led to a change in sign of the net ecosystem carbon exchange of a tropical forest. To help overcome such problems, Gu et al. (2005) developed an objective method to determine the threshold value of $u_{*}$. While the $u_{*}$ filter method is the most commonly used approach to deal with stably stratified canopy flows, it is recognized that estimation of nighttime ecosystem exchange needs to be re-investigated both on theoretical and experimental grounds (Falge et al., 2001a,b).

We propose an alternative to the $u_{*}$ filter approach that makes use of the different time scales for the decline of the turbulent flux, the rate of change of storage and the onset of advection with the development of stable stratification within the canopy. We use the maximum in the sum of the turbulent flux and the change in storage obtained in the early evening to develop relationships between NCE and independent variables, such as soil temperature and moisture. This approach significantly reduces biases and uncertainty in the micrometeorological NCE measurements as verified by comparison against independent chamber measurements of soil and plant respiration.

\section{Methods}

\subsection{Site}

The Tumbarumba flux station $\left(35^{\circ} 39^{\prime} 20.7^{\prime \prime} \mathrm{S}, 148^{\circ} 09^{\prime} 07.5^{\prime \prime} \mathrm{E}\right.$, elevation $1200 \mathrm{~m}$ ) is located in the southeastern highlands of New South Wales, Australia (Leuning et al., 2005). The site is in relatively complex terrain (Fig. 1), leading to a variation of $-6^{\circ}$ to $+2^{\circ}$ in the angle between the mean wind vector and the azimuthal-average vertical direction (Finnigan et al., 2003). Vegetation at the site consists of a $40 \mathrm{~m}$ tall, open wet sclerophyll forest with the dominant species Eucalyptus delegatensis R.T.Baker and Eucalyptus dalrympleana Maiden. The leaf area index $\left(L_{\mathrm{ai}}\right)$ of the trees is $1.4 \mathrm{~m}^{2} \mathrm{~m}^{-2}$, while the understorey is sparsely covered with shrubs and grass which have a $L_{\mathrm{ai}}$ of $1.5 \mathrm{~m}^{2} \mathrm{~m}^{-2}$ (Keith, personal communication, 2006). The site is relatively homogeneous in terms of species composition, density and tree height within a radius of more than $5 \mathrm{~km}$.

\subsection{Instrumentation and data processing}

Extensive descriptions of the instrumentation and the processing of micrometeorological data are given in Leuning et al. (2005), while Keith and Wong (2006) describe the measurement of soil

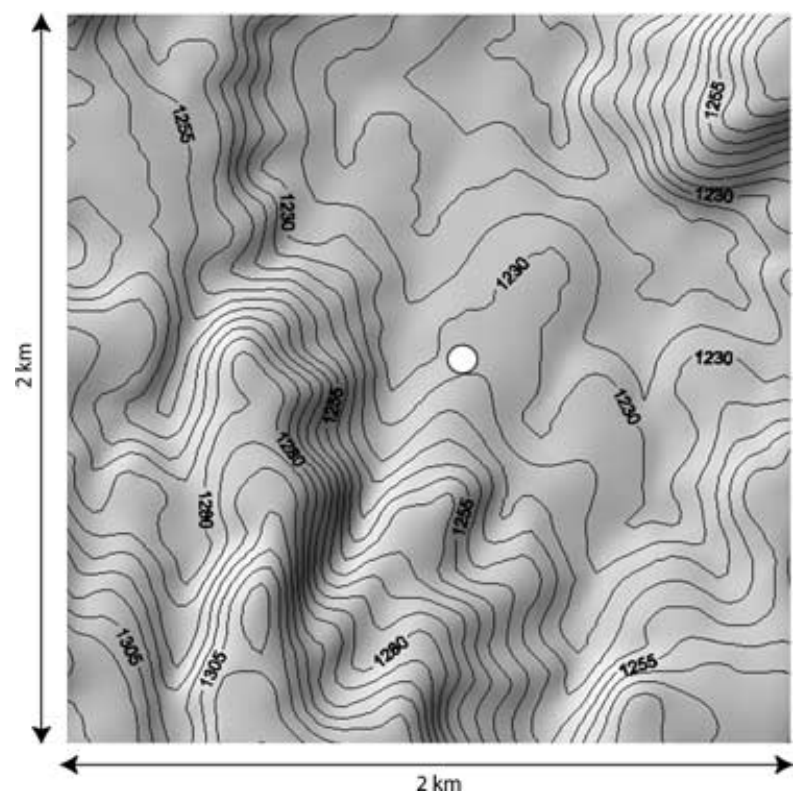

Fig. 1. Relief map of the terrain surrounding the tower (indicated with white dot) located at Tumbarumba.

respiration using static chambers. Briefly, turbulent fluxes were measured using an ultra sonic anemometer thermometer (Type HS, Gill Instruments Ltd., Lymington, UK), and an open-path infrared gas analyser (Li7500, Li-Cor Inc., Lincoln, NE, USA). The instruments were mounted $1.5 \mathrm{~m}$ above the top of a $70 \mathrm{~m}$ high triangular mast with sides of $0.45 \mathrm{~m}$ in length. Signals were sampled at $20 \mathrm{~Hz}$ and fluxes were calculated using 1-hr block averages. Coordinate rotations were calculated separately for each hour and applied such that the mean lateral and vertical wind velocity components are forced to zero. To calculate the change in storage term, $\mathrm{CO}_{2}$ concentrations were measured at nine heights $(0.5,4.6,10.2,18.1,26.3,34.4,42.6,54.4$ and $70.1 \mathrm{~m})$ using a closed path IRGA (Li6262, Li-Cor Inc.) and gas switching valves. Air sampling for the $\mathrm{CO}_{2}$ concentration measurements was designed to ensure that air passing sequentially through the analyser from each level had entered the tubing inlets on the mast at the same time. This was achieved using variable flow rates and tubing lengths for each sampling height and provided quasiinstantaneous profiles every $225 \mathrm{~s}$. To avoid cross-contamination of measurements between levels, the analyser was purged for $15 \mathrm{~s}$ after switching between gas streams before taking 10 samples during the next $10 \mathrm{~s}$.

Soil respiration was measured using chambers placed within a circular area with a $1 \mathrm{~km}$ radius, centered on the flux tower. Sampling density in the radial direction was based on the footprint model of Schuepp et al. (1990), while sampling was random within each annulus surrounding the tower. Thus, soil respiration was sampled with a similar weighting to contributions of the upwind source area to the above-canopy flux measurements. Soil respiration was measured by placing on the soil static, 
cylindrical chambers (volume 6.91 , area $0.08 \mathrm{~m}^{2}$ ) containing a tray of soda lime to absorb $\mathrm{CO}_{2}$ (Keith and Wong, 2006). Separate measurements were made during daylight and nighttime during week-long campaigns in November of 2003, and in February, May and August of 2004. Leaf dark respiration was measured at night with an infrared gas analyser (IRGA) (Li6400, Li-Cor Inc., Lincoln, NE, USA) using an open flow-through method, in a temperature-controlled leaf cuvette (e.g. Livingston and Hutchinson, 1995). Measurements over the temperature range $5^{\circ}-30{ }^{\circ} \mathrm{C}$ allowed derivation of temperature response functions for respiration. Wood respiration was measured in metal/acrylic chambers attached to tree trunks, branches and coarse roots. The efflux of $\mathrm{CO}_{2}$ from trunks and roots was measured using the closed dynamic method, where $\mathrm{CO}_{2}$ concentration increase over time was measured with an LI6200 gas analyser (Li-Cor Inc., Lincoln, NE, USA; Keith, personal communication, 2006).

An intensive field campaign was run in March 2005 to measure the relative contributions of turbulent flux, change in storage, horizontal advection and vertical advection to the mass balance of a $50 \times 50 \times 6 \mathrm{~m}$ control volume on the forest floor and located $240 \mathrm{~m}$ southwest of the main mast (Leuning et al., unpublished). The measurements were used to determine errors in the estimates of nocturnal respiration when only the turbulent flux and change in storage terms in the mass balance equations are considered, and the horizontal and vertical advection terms are neglected. Micrometeorological measurements of respiration from the soil and vegetation in the lowest $6 \mathrm{~m}$ were also compared to intensive measurements of respiration using chambers.

Additional measurements at the top of the tower include incoming solar radiation (CM11, Kipp and Zonen, Delft, NL) and air temperature and humidity (50Y RH/T sensor, Vaisala, Helsinki, FI) mounted in a fully aspirated radiation shield. Profiles of temperature (copper constantan thermocouples mounted beneath a radiation shield), wind speed and direction (WindSonic, Gill Instruments Ltd., Lymington, UK) were measured. Rainfall was measured above the canopy and at ground level with tipping bucket rain gauges (TB3, Hydrological Services Pty Ltd, NSW, Australia). Soil temperatures were measured at 0.02 and $0.05 \mathrm{~m}$ depth with thermocouples manufactured in our laboratory. Measurements of three thermocouples were averaged for each depth. All signals were sampled at either 1 or $0.1 \mathrm{~Hz}$ and averaged for $1 \mathrm{hr}$. Soil moisture content was measured using time domain reflectometry in four locations and four depths each. Measuring interval is $1 \mathrm{hr}$.

\subsection{Derivation of $N C E$}

The nocturnal net ecosystem exchange (NCE), is defined as the net carbon flux through the top and the side planes of a control volume below a reference height $h_{\mathrm{r}}$. Assuming incompressibility, and neglecting horizontal turbulent flux divergence, the exchange rate between soil-forest and atmosphere is given by (Finnigan,
1999; Feigenwinter et al., 2004):

$$
\begin{aligned}
& N C E=\overline{w^{\prime} c^{\prime}}\left(h_{\mathrm{r}}\right)+\int_{0}^{h_{\mathrm{r}}} \frac{\overline{\partial c(z)}}{\partial t} d z \\
& \text { I II } \\
& +\int_{0}^{h_{\mathrm{r}}}\left(\bar{u}(z) \frac{\partial \bar{c}(z)}{\partial x}+\bar{v}(z) \frac{\partial \bar{c}(z)}{\partial y}\right) d z \\
& \text { III } \\
& +\int_{0}^{h_{\mathrm{r}}}\left(\bar{w}(z) \frac{\partial \bar{c}(z)}{\partial z}\right) d z \\
& \text { IV }
\end{aligned}
$$

where $x, y, z$ define the Cartesian coordinates, $u, v, w$ are the longitudinal, lateral and vertical wind components, respectively, and $c$ stands for the molar concentration of carbon dioxide. Overbars denote time averages and primes departures of the instantaneous values from the mean. Only the vertical turbulent flux (term I on the RHS of eq. 1) will be significant under strong wind conditions in an ideal site in homogeneous, flat terrain. Term II, the rate of change in storage of $\mathrm{CO}_{2}$ in the layer below $h_{\mathrm{r}}$, becomes significant during the transition from unstable to stable conditions, typically at dusk, with the reverse occurring at dawn. This term becomes insignificant over long averaging periods because $\mathrm{CO}_{2}$ stored in the air layer overnight is dissipated with the onset of turbulence in the following morning. Neglect of the advection terms (III and IV) will cause significant errors in the mass budget if there are systematic differences in horizontal and vertical transport of $\mathrm{CO}_{2}$ through the walls and upper surface of the control volume. Errors due to advection will be most severe under conditions of low windspeeds and stable atmospheric stratification in all but completely flat terrain. Aubinet et al. (2005), Feigenwinter et al. (2004), Staebler and Fitzjarrald (2004), among many others, found that sum of the turbulent flux plus change in storage underestimated $N C E$ because of advection of $\mathrm{CO}_{2}$ resulting from drainage of cold air in the layer below the flux instruments.

Biological measurements of respiration from soil $\left(R_{\mathrm{s}}\right)$, leaves $\left(R_{\mathrm{l}}\right)$ and wood $\left(R_{\mathrm{w}}\right)$ provide an independent method of deriving the NCE, where

$N C E=R_{\mathrm{s}}+R_{\mathrm{l}}+R_{\mathrm{w}}$.

Keith et al. (2006) describe the methods used to extrapolate chamber measurements of respiration on leaves wood and soil to the whole site. Leaf respiration was measured per leaf surface area and scaled to site using $L_{\mathrm{ai}}$ information. Wood respiration (stem, branch and root fraction) was measured per sap wood volume and scaled to site using tree inventory data. Soil respiration was scaled to the area of the plots and then a weighted average is taken for scaling it up to site.

\section{Results and discussion}

Figure 2 shows the nocturnal eddy fluxes (term I, eq. 1) and the sum of the eddy fluxes and change in storage (terms I + II, 


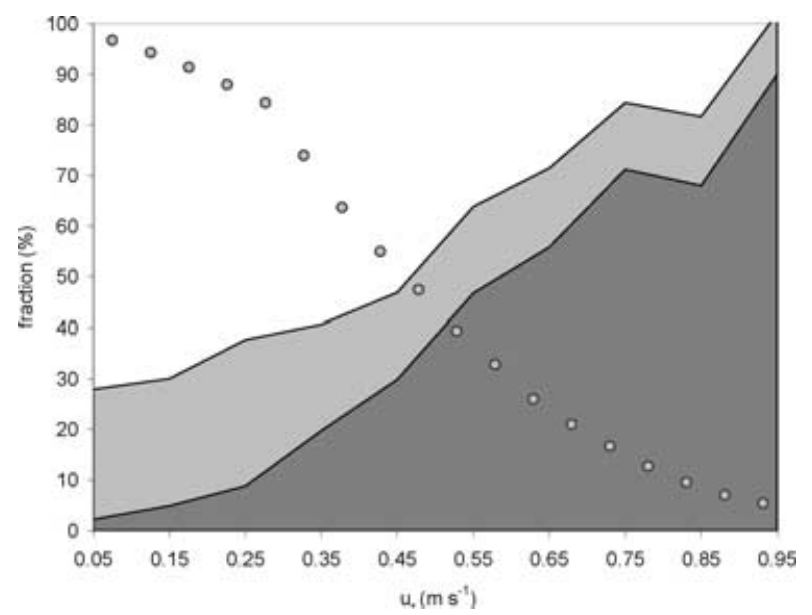

Fig. 2. Fraction of turbulent flux (dark grey area) and sum of turbulent flux and storage term (light grey area) to nighttime respiration determined from chambers measurements [2001-2005]. Dots represent the cumulative frequency of $u_{*}$ exceeding a given value.

eq. 1) as a function of $u_{*}$. Hourly fluxes were normalized by the corresponding nighttime respiration as estimated from the temperature-dependence of respiration of soil, wood and leaves obtained from chamber measurements (eq. 2). The composite of 5 -yr of data in Fig. 2 shows that the proportion of the total $N C E$ measured by the eddy flux increases steadily from $<5 \%$ at $u_{*}=0.05 \mathrm{~m} \mathrm{~s}^{-1}$ to $>70 \%$ at $u_{*}=0.85 \mathrm{~m} \mathrm{~s}^{-1}$. The contribution of the change in storage term is largest at low $u_{*}$ and declines slowly at higher $u_{*}$ values, but only at $u_{*}>0.95 \mathrm{~m} \mathrm{~s}^{-1}$ do the sum of terms I and II in eq. 1 match the respiration estimated from the chamber measurements. There is also no clear $u_{*}$ threshold above which the normalized fluxes remain constant, and applying a $u_{*}$-filter on the Tumbarumba data set leads to poor results. The cumulative probability distribution for $u_{*}$ exceeding a given value is represented by the dots in Fig. 2. The distribution shows that the sum of the eddy flux and change in storage increases with $\mathrm{u}^{*}$ but that the number of usable data points decreases rapidly. Use of a high $u_{*}$ threshold, thus, severely restricts the amount of data available for constructing relationships between NCE and soil temperature, for example.

The reason for this behaviour is illustrated in Fig. 3, which presents time series of $u_{*}$ and $\mathrm{CO}_{2}$ concentrations measured at nine heights between 0.5 and $71.1 \mathrm{~m}$ on three nights in March 2005. On the first night, conditions were calm, with strong stable thermal stratification and the development of strong concentration gradients. Note that concentrations increased steadily only in the first few hours after dusk and then remained approximately steady until dawn. Advection of $\mathrm{CO}_{2}$ in the layer below $h_{\mathrm{r}}$ explains these results because the reduction in the magnitude of term II in eq. (1) was not matched by an increase in the eddy flux through the top of the control volume. Changes in respiration rates do not explain the results because, there is expected to be only a small reduction in biologically controlled respiration as the soil and vegetation cooled slowly over night. Without advection, the concentrations would have continued to increase steadily throughout the night. The second, intermittent night, was characterized by well-mixed conditions before midnight and a period of high stability around midnight. Strong $\mathrm{CO}_{2}$ concentration gradients developed as soon as $u_{*}$ dropped below $0.25 \mathrm{~m} \mathrm{~s}^{-1}$, leading to significant changes in storage below $h_{\mathrm{r}}$. During the second part of the night, a considerable $\mathrm{CO}_{2}$-gradient was maintained despite the observed high-turbulence levels. This indicates that the $u_{*}$ values measured well above the canopy are not always representative of within-canopy processes. Continuous high-turbulence levels and near-neutral stability as observed throughout the third night $\left(u_{*}>0.75 \mathrm{~m} \mathrm{~s}^{-1}\right)$, are needed to maintain a coupled flow and good mixing associated with small vertical $\mathrm{CO}_{2}$ concentration gradients and associated small changes in storage.

Figure 4 shows that eddy fluxes at $70.1 \mathrm{~m}$ are small during night and that there is a maximum of $\sim 4 \mu \mathrm{mol} \mathrm{CO} \mathrm{Cm}^{-2} \mathrm{~s}^{-1}$ in the sum of terms I and II in eq. (1) in the early evening which then decays to $\sim 1 \mu \mathrm{mol} \mathrm{m}{ }^{-2} \mathrm{~s}^{-1}$ in the second part of the night. A similar decrease in the sum of terms I and II in the second half of the night has been observed by Aubinet et al. (2005) at several forested sites characterized by very different topographies,

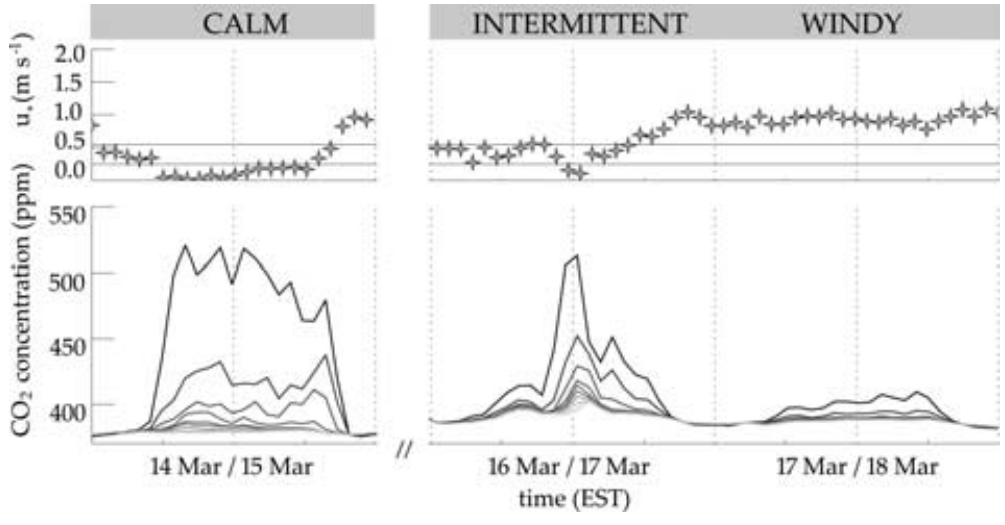

Fig. 3. Top panel: Time series for friction velocity $u_{*}$. Horizontal lines indicate 0.25 and $0.55 \mathrm{~m} \mathrm{~s}^{-1}$ levels. Bottom panel: time series of $\mathrm{CO}_{2}$ concentrations measured at 9 heights, where the darkest grey indicates the measurement closest to the ground, and the brightest grey, the measurement at reference height in $70 \mathrm{~m}$. 


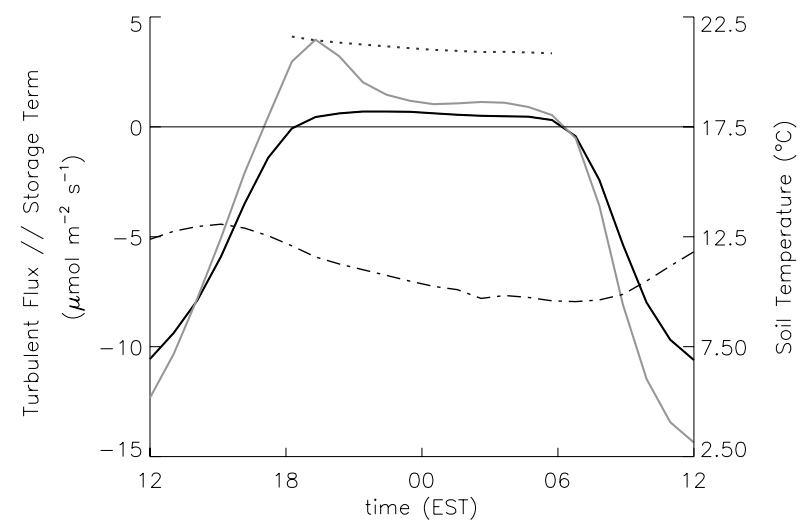

Fig. 4. Mean daily course [2001-2005] of the turbulent flux of $\mathrm{CO}_{2}$ (black line), the sum of eddy flux and change in storage term (grey line) and the soil temperature at $0.02 \mathrm{~m}$ (dash dotted line). The dotted line represents total nighttime respiration derived from chamber measurements.

vegetation cover and wind regimes. The observed decrease exceeds the expected reduction in respiration due to decreasing soil and plant temperatures overnight, a conclusion supported by comparison with $N C E$ derived from independent chamber measurements of respiration from soil leaves and wood (dashed line). Clearly, micrometeorological measurements on a single tower underestimate $N C E$ in the second part of the night, even though the Tumbarumba flux station is located in fairly moderate topography. The results provide strong evidence that a substantial fraction of the NCE is not captured because of horizontal and vertical advection of $\mathrm{CO}_{2}$ below the measurement height.

Figure 4 shows that there is very good agreement between the biological and micrometeorological estimates of NCE in the early evening, suggesting that this maximum value of $N C E\left(R_{\max }\right)$ should be used to derive relationships between net ecosystem respiration and independent variables, such as air or soil temperatures and soil moisture content. Using $R_{\max }$ will therefore provide better estimates of $N C E$ for the ecosystem than those obtained using the average of terms I plus II for the whole night or from applying the $u_{*}$ filter, which was shown above not to have a threshold value.

Selection of the maximum value of terms I plus II in eq. (1) early in the evening is based on the hypothesis that there are different time scales for the decline of the turbulent flux, the rate of change of storage and the onset of advection with the development of stable stratification in the canopy. This provides a short period in the early evening when terms I and II are dominant and the advections terms (III and IV) are still small. Later in the evening, radiative cooling leads to the development of strong vertical temperature gradients, a suppression of turbulence and an enhancement of advection. The bulk Richardson number $\left(R_{i}=70\left(g / T_{v 70}\right)\left(\theta_{v 70}-\theta_{v 1}\right) /\left(U_{70}-U_{1}\right)^{2}\right)$ calculated over the layer from the highest $(70 \mathrm{~m})$ to the lowest measurement height $(1 \mathrm{~m})$ provides a measure of the stability within the canopy.

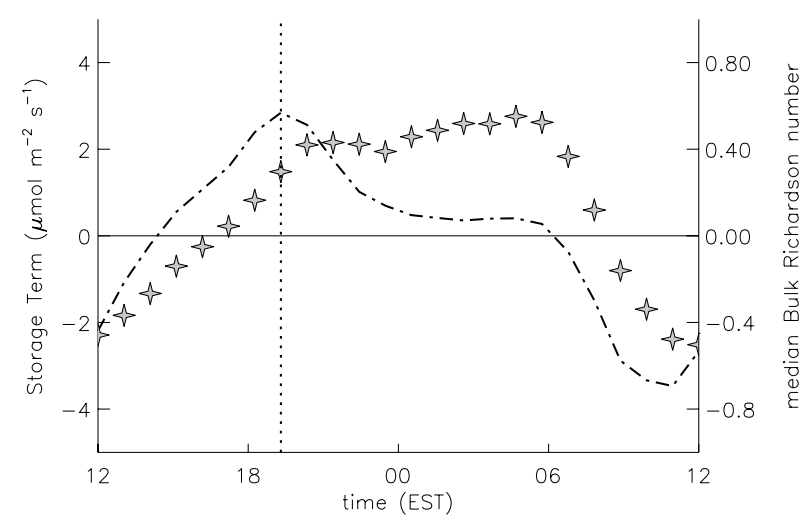

Fig. 5. Mean daily course [September 2004-March /2005] of storage term (dash dotted line) and the median of the bulk Richardson number.

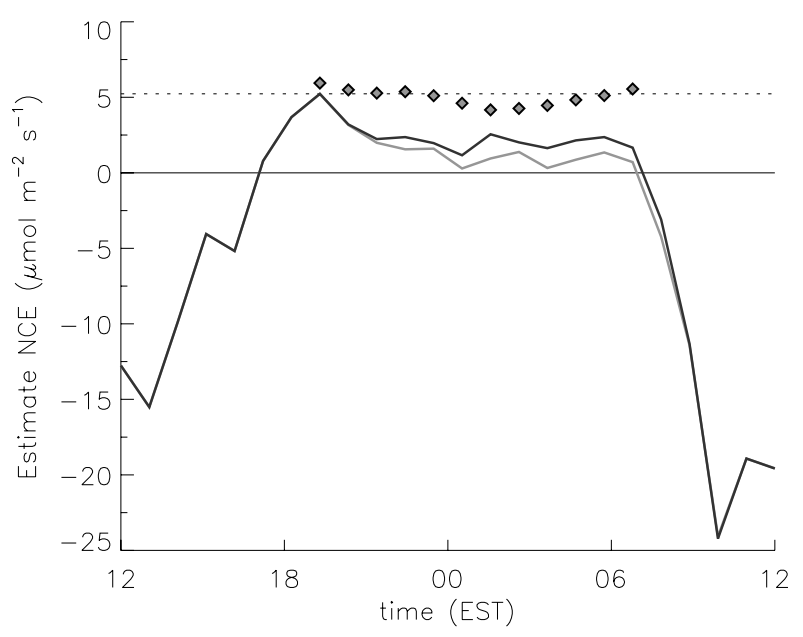

Fig. 6. Mean daily course (8-17 March 2005) of the sum of eddy flux and change in storage term (grey line), and sum of eddy flux, change in storage and horizontal advection from 0-6 $\mathrm{m}$ (black line). Symbols stand for the turbulent flux of $\mathrm{CO}_{2}$, measured in the night from 17-18 March, when turbulence levels were continuously very high.

Figure 5 shows that $R_{i}$ becomes positive in the late afternoon and increases continuously until around 20:00 when it reaches a relatively constant value. The change of storage of $\mathrm{CO}_{2}$ starts to decrease strongly at this time, suggesting that when flow within the canopy is sufficiently stable, turbulence is suppressed and gravity currents drain the $\mathrm{CO}_{2}$ enriched air away.

Data obtained during an intensive field campaign in March 2005 were used to test this hypothesis. Chambers were used to measure respiration by the soil, leaves and wood was measured (Keith and Wong, 2006), and all components of the $\mathrm{CO}_{2}$ mass balance of a $50 \times 50 \times 6 \mathrm{~m}^{3}$ control volume located on the forest floor were measured during the campaign. Figure 6 confirms that the horizontal advection term becomes significant only after $R_{\max }$ is reached. It also shows that there is a close match between estimates of respiration from the chamber measurements (dashed line) and the early-evening maximum in the sum of the 
Table 1. Comparison of several estimates of NCE $\left(\mu \mathrm{mol} \mathrm{m}^{-2} \mathrm{~s}^{-1}\right)$ for a dataset gathered during an intensive measurement campaign in March 2005

\begin{tabular}{lllll}
\hline NCE (total) & & & & NCE (max) \\
\hline Turbulent & Turbulent & Turbulent & Chamber & Turbulent \\
Flux & Flux + & Flux $^{\mathrm{a}}$ & measurements & Flux + \\
& Storage & & & Storage \\
$(10)$ & $(10)$ & $(1)$ & $(10)$ & $(10)$ \\
0.46 & 1.70 & 4.97 & 5.18 & 5.23 \\
\hline
\end{tabular}

The numbers in brackets indicate the number of averaged days.

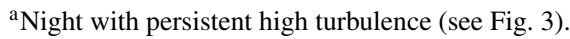

eddy flux at $71 \mathrm{~m}$ plus the change in storage term (grey line). The subsequent steady decline in the sum of terms I and II was not matched by the biological estimates, which showed only a small decrease due to a drop in temperature overnight. Micrometeorological estimates of the nocturnal flux were increased by inclusion of the horizontal advection term from the advection study (black line) but the sum was still less than chamber values. The underestimate partially arises because the horizontal advection term is only for the lowest $6 \mathrm{~m}$ of the forest, not for the whole canopy, which rises to $40 \mathrm{~m}$. The remaining component of the underestimated flux is due to vertical advection (Finnigan, 1999). Terms II, III, and IV of eq. (1) are expected to be small under well-mixed conditions, as confirmed by the close agreement between respiration estimated from the chamber measurements (dashed line) and eddy fluxes measured on a very windy night during the intensive field campaign (dotted line).

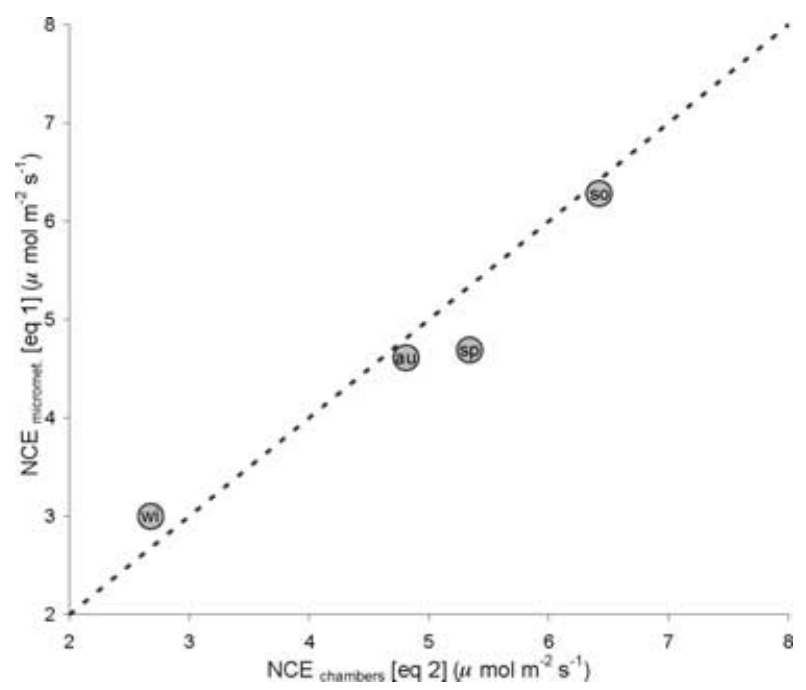

Fig. 7. $N C E$ derived using $R_{\max }$ versus $N C E$ derived by independent chamber measurements carried out in intensive measuring periods in all four seasons $(\mathrm{au}=$ autumn, wi $=$ winter, $\mathrm{sp}=$ sping, $\mathrm{so}=$ summer $)$.
Table 1 confirms that $R_{\max }$ provides an excellent estimate of NCE when compared to the chamber measurements. It also shows that turbulent fluxes alone, or in combination with the change in storage term, significantly underestimate the NCE unless conditions of continuous very high turbulence are met (Fig. 6).

Micrometeorological measurements were used to develop relationships between $N C E$ and soil temperature using $R_{\max }$. In Fig. 7, these values are compared against results obtained from concurrent chamber measurements made during four intensive, week-long campaigns spanning a full year. The results are in excellent agreement and strongly support the use of the $R_{\max }$ to determine $N C E$.

\section{Conclusions}

Micrometeorological methods have distinct advantages for deriving net ecosystem exchange (NEE) of $\mathrm{CO}_{2}$ because they sample a large source area without modifying the environment. During well-mixed, daytime conditions, turbulent fluxes and change in storage measured on a single tower in flat-to-moderate topography with homogeneous vegetation will equal net ecosystem exchange because horizontal and vertical advection in the layer below the instruments will then be negligible. This is not the case when the atmosphere is stably stratified, as often occurs at night under clear skies when advection terms are significant. A common approach is to exclude nighttime flux measurements below a critical $u_{*}$ threshold, when turbulence levels are low, and to use the remaining data to develop relationships between one or more independent environmental variables and the turbulent fluxes plus changes in storage in the layer below the measurement height. This assumes that advection is insignificant above the $u_{*}$ threshold, but this study has shown that there is no $u_{*}$ unique threshold at our site and that there is a significant underestimation of NCE for all but very high $u_{*}$ values.

We have shown that there is a maximum in the sum of the turbulent flux and storage of $\mathrm{CO}_{2}$ in the early evening, $R_{\max }$, that is in close agreement with concurrent and independent estimates of net carbon exchange from soil and plant chambers. The micrometeorological measurements in the early evening are likely to be unaffected by advection as there is a time delay between the onset of radiative cooling and the development of a temperature gradient which is strong enough to cause a decoupling of within and above canopy flow. This allows successful use of $R_{\max }$ to construct relationships between NCE and independent variables, such as soil temperature. Comparison with the chamber measurements showed that temperature response functions for $N C E$ developed using the maximum fluxes in the early evening leads to excellent agreement between the two independent methodologies. Using the new parameterization leads to realistic values of nighttime respiration, and therefore to improved estimates of net ecosystem exchange $N E E$, the annual sum of daytime and nighttime exchanges of $\mathrm{CO}_{2}$. 


\section{Acknowledgments}

Special acknowledgement is given to Dale Hughes, Mark Kitchen and Steve J. Zegelin for support given in construction, maintenance and expansion of the flux station as well as for data transfer, processing, control and archiving. We are grateful to the Forestry Department, New South Wales, for permission to install the flux station in the Bago State Forest. This work was supported in part by a grant from the Australian Greenhouse Office (19999-20005) through the Australian Climate Change Science Program and its predecessors.

\section{References}

Aubinet, M., Grelle, A., Ibrom, A., Rannik, Ü., Moncrieff, J., Foken, T. and co-authors. 2000. Estimates of the annual net carbon and water exchange of European forests: the EUROFLUX methodology. Adv. Ecol. Res. 30, 114-175.

Aubinet, M., Berbigier, P., Bernhofer, Ch., Cescatti, A., Feigenwinter, Ch., and co-authors. 2005. Comparing $\mathrm{CO}_{2}$ storage and advection conditions at night at different Carboeuroflux sites. Bound. Layer Meteorol. 116, 63-94.

Baldocchi, D. D., Valentini, R., Running, S., Oechel, W. C. and Dahlman, R. 1996. Strategies for measuring and modelling carbon dioxide and water vapour fluxes over terrestrial ecosystems. Glob. Change Biol. 2, 159-167(1996).

Barford, C. C., Wofsy, S. C., Goulden, M. L., Munger, J. W., Pyle, J. H., and co-authors. 2001. Factors controlling long- and short term sequestration of atmospheric $\mathrm{CO}_{2}$ in a mid latitude forest. Science 294, 1688-1691.

Curtis, P. S., Hanson, P. J., Bolstad, P., Barford, C., Randolph, J. C. and co-authors. 2002. Biometric and eddy-covariance based estimates of annual carbon storage in five eastern North American deciduous forests. Agric.For.Meteorol. 113, 3-19.

Falge, E., Baldocchi, D., Olson, R. J., Anthoni, P., Aubinet, M. and coauthors. 2001a. Gap filling strategies for defensible annual sums of net ecosystem exchange. Agric.For.Meteorol. 107, 43-69.

Falge, E., Baldocchi, D., Olson, R. J., Anthoni, P., Aubinet, M. and coauthors. 2001b. Gap filling strategies for longterm energy flux data sets. Agric.For.Meteorol. 107, 71-77.

Feigenwinter, Ch., Bernhofer, Ch. and Vogt, R. 2004. The influ ence of advection on the short term $\mathrm{CO}_{2}$ budget in and above a forest canopy. Bound. Layer Meteorol. 113, 201-224.

Finnigan, J. J. 1999. A comment on the paper by Lee (1998): "On micrometeorological observations of surface-air exchange over tall vegetation.” Agric. Forest Meteorol. 97, 55-64.

Finnigan, J. J., Clement, R., Malhi, Y., Leuning, R. and Cleugh, H. A. 2003. A reevaluation of longterm flux measurement techniques. Part I: averaging and coordinate rotation. Q. J. Roy. Meteorol. Soc. 130, 129.

Finnigan, J. J. and Belcher, S. E. 2004. Flow over a hill covered with a plant canopy. Q. J. Roy. Meteorol. Soc. 130, 1-29.

Goulden, M. L., Munger, J. W., Fan, S. M., Daube, B. C. and Wofsy, S. C. 1996. Measurements of carbon sequestration by longterm eddy covariance: methods and a critical evaluation of accuracy. Global Change Biol. 2, 169-182.

Gu, L., Falge, E. M., Boden, T., Baldocchi, D. D., Black, T. A. and coauthors. 2005. Objective threshold determination for nighttime eddy flux filtering. Agric.For.Meteorol. 128, 179-197.

Katul, G. G., Finnigan, J. J., Poggi, D., Leuning, R. and Belcher, S. E. 2006. The influence of hilly terrain on canopy atmosphere carbon dioxide exchange. Bound. Layer Me teorol. 118, 189-216.

Keith, H. and Wong, S. C. 2006. Measurement of soil $\mathrm{CO}_{2}$ efflux using soda lime absorption: both quantitative and reliable. Soil Biol. Biochem. 38 (5), 1121-1131.

Leuning, R., Cleugh, H. A., Zegelin, S. J. and Hughes, D. 2005. Carbon and water fluxes over a temperate Eucalyptus forest and a tropical wet/dry savanna in Australia: measurements and comparison with MODIS remote sensing esti mates. Agric.For.Meteorol. 129, 151173.

Livingston, G. P. and Hutchinson, G. L. 1995. Enclosure-based measurement of trace gas exchange: applications and sources of error. In: Methods in Ecology. Biogenic Trace Gases: Measuring Emissions from Soil and Water (eds. P. A. Matson, R. C. Harris). Blackwell Scientific Publ., pp. 14-51.

Miller, S. D., Goulden, M. L., Menton, M. C., da Rocha, H. R., de Freitas, H. C. and co-authors. 2004. Biometric and micrometeorological measurements of tropical forest carbon balance. Ecological Applications 14(4), 114-126.

Moncrieff J. B., Malhi Y. and Leuning R. 1996. The propagation of errors in long-term measurements of land-atmosphere fluxes of carbon and water. Global Change Biology 2, 231-240.

Schuepp, P. H., Leclerc, M. Y., MacPherson, J. I. and Desjardins, R. L. 1990. Footprint prediction of scalar fluxes from analytical solutions of the diffusion equation. Boundary Layer Me teorol., 50, 355374.

Staebler, R. M. and Fitzjarrald, D. R. 2004. Observing subcanopy $\mathrm{CO}_{2}$ advection. Agric.For.Meteorol. 122, 139-156.

Turnipseed, A. A., Anderson, D. E., Blanken, P. D., Baugh, W. and Monson, R. K., 2003. Airflows and turbulent flux measurements in mountainous terrain, Part 1: canopy and local effects. Agric. For. Meteorol. 119, pp. 1-21.

Wang, Y. P., Leuning, R., Cleugh, H. A. and Coppin, P. A. 2001. Parameter estimation in surface exchange models using nonlinear inversion: how many parameters can we estimate and which measurements are most useful? Global Change Biology 7 (5), 495510 . 